\title{
Skin disinfection practice before skin anaesthesia, prior to neuraxial blockade: a survey of government hospital practices in South Africa
}

\author{
DF Coetzee, ${ }^{1}$ A Senekal, ${ }^{2}$ PA Scheepers ${ }^{2}$ \\ ${ }^{1}$ Department of Anaesthesiology and Critical Care, Faculty of Medicine and Health Sciences, University of Stellenbosch and Tygerberg \\ Academic Hospital, Tygerberg, South Africa \\ ${ }^{2}$ Private Practice, Stellenbosch \\ Corresponding author, email: dirkfcoetzee@sun.ac.za
}

Background: Infectious complications following neuraxial block, although being of low incidence, may lead to morbidity and mortality. Two common methods utilised for skin disinfection before skin anaesthesia prior to a neuraxial block are the isopropanol only method (isopropanol method) and the full aseptic technique (classic method). The objective of this study was to survey government-employed South African anaesthesiologists' preference regarding the disinfection practices before the administration of local anaesthetic agents to the skin prior to the performance of a neuraxial block.

Methods: Ethics approval was obtained prior to commencing the study. An electronic, web-based questionnaire in the form of a survey was distributed to various anaesthetic departments in various government teaching hospitals in South Africa. Descriptive statistics were used on the raw data using the Fisher exact test to measure associations between the different categorical variables. Results: A significant response rate of $60.3 \%$ was achieved. Regarding subarachnoid blocks, more than half of the participants (52.0\%) that participated in the survey utilise the isopropanol method whereas less than half of the participants utilise the isopropanol method when performing an epidural block. Close to $75 \%$ of participants with zero to five years anaesthetic experience prefer the isopropanol method whilst only $20.9 \%$ of anaesthetists with more than ten years' experience prefer the isopropanol method when performing a subarachnoid block $(p<0.01)$.

Conclusion: Both methods described in this study (classic and isopropanol methods) are practised commonly by the participants in the survey and neither the classic nor the isopropanol method dominates. Local guidelines need to address the technique used to disinfect the skin before the administration of the local anaesthetic agent to the skin prior to performing a neuraxial block.

Keywords: anaesthesia, local anaesthetic agent, neuraxial block, aseptic technique, guidelines

\section{Introduction}

For the past thirty years, it has been a standard of care to utilise epidurals or subarachnoid opioids and/or local anaesthetic agents during labour and major thoracic and abdominal surgery. The use of a neuraxial block has become part of the everyday armamentarium of the anaesthetist.

That being said, infectious complications associated with neuraxial block are well described and include, but are not limited to, epidural abscess formations, necrotising fasciitis, purulent meningitis, and arachnoiditis. These complications may lead to serious morbidity and mortality. The reported incidence of infectious complications following neuraxial block is varied, but reported ranges are between $0.02 \%$ to $0.07 \% .^{2-6}$

There are many factors that increase the patient's risk of septic complications following a neuraxial block. One of these factors is improper aseptic technique. If skin overlying the site for a neuraxial block is not disinfected properly prior to the administration of a local anaesthetic agent to the skin, the possibility exists for bacterial seeding to occur to the subcutaneous tissue. With that in mind, after skin disinfection with $0.5 \%$ chlorhexidine in $70 \%$ alcohol or $10 \%$ povidone-iodine, bacteria are still able to survive on the epidermal layer of the skin, especially in and around the hair follicles. ${ }^{6}$ Sato et al. stated that organisms residing in the deeper layers of the skin are protected from eradication by disinfectants. ${ }^{6} \mathrm{~A}$ subsequent neuraxial needle introduced through the contaminated tissue could potentially contaminate the subarachnoid and/or epidural spaces. This 'seeding theory' has however not been proven in vitro nor in vivo.

No literature exists, neither locally nor internationally, on the practice of skin disinfection before skin anaesthesia prior to neuraxial block. At Tygerberg Hospital, a tertiary level government referral hospital, there exist two methods commonly used for skin disinfection prior to the administration of the local anaesthetic agents to the skin before a neuraxial block (Table I):

- The classic method

- The isopropanol method

These two methods of skin disinfection before local anaesthetic agent administration for the purpose of skin anaesthesia are similar in most aspects. The key difference lies in the way the performer of the neuraxial block obtains skin disinfection before the skin anaesthesia. In the classic method, the performer utilises $0.5 \%$ chlorhexidine in $70 \%$ alcohol after donning sterile attire and then proceeds to draping of the patient and administering the skin anaesthetic. When utilising the isopropanol method, however, the performer uses a 70\% isopropanol impregnated swab to disinfect the skin prior to the skin anaesthetic. Only then does the performer proceed to donning sterile attire and full disinfection for the neuraxial block. 
Table I. Description of two methods used to disinfect the skin before local anaesthetic agent administration to skin prior to neuraxial block

\begin{tabular}{|c|c|c|c|}
\hline & & Classic method & Isopropanol method \\
\hline \multirow{8}{*}{$\begin{array}{l}\text { Steps taken in the performance } \\
\text { of the neuraxial technique }\end{array}$} & 1. & Standard ASA monitoring and IV access & Standard ASA monitoring and IV access \\
\hline & 2. & Patient positioning & Patient positioning \\
\hline & 3. & Facemask, handwash and gloves & Local anaesthetic agent is drawn up $\dagger$ \\
\hline & 4. & $\begin{array}{l}\text { Skin disinfection with } 0.5 \% \text { chlorhexidine in } \\
70 \% \text { alcohol and draping }\end{array}$ & Isopropanol used to disinfect skin \\
\hline & 5. & $\begin{array}{l}\text { Local anaesthetic agent drawn up in sterile } \\
\text { fashiont }\end{array}$ & Local anaesthetic agent is administered to skin \\
\hline & 6. & $\begin{array}{l}\text { Local anaesthetic agent is administered to } \\
\text { skin }\end{array}$ & Facemask, handwash and gloves* \\
\hline & 7. & Wait for local anaesthesia to take effect & $\begin{array}{l}\text { Skin disinfection with } 0.5 \% \text { chlorhexidine in } 70 \% \text { alcohol } \\
\text { and draping }\end{array}$ \\
\hline & 8. & Neuraxial block performed & Neuraxial block performed \\
\hline
\end{tabular}

* Anaesthesiologist dons sterile attire. † Local anaesthetic agent used for skin analgesia. Similarities highlighted in green. Major differences highlighted in red and yellow.

There are three major perceived benefits of utilising the isopropanol method:

i. The anaesthesiologist uses anatomical landmarks and identifies the exact site for the neuraxial block before he/ she dons sterile attire. The skin weal that is created by the administration of the local anaesthetic agent to the skin acts as an iatrogenic landmark for the subsequent neuraxial needle placement. This is perceived to minimise the amount of physical contact that takes place after donning sterile gloves, thus limiting potential contamination with the gloves.

ii. The isopropanol method allows for effective use of time after the local anaesthetic agent has been administered. The time to peak effect of subcutaneous lignocaine is two to five minutes. ${ }^{7}$ While the local anaesthetic agent is taking effect, the anaesthesiologist dons sterile gloves and drapes the patient. This is perceived to save theatre time when compared to the classic method and the subsequent theatre costs.

iii.The isopropanol method potentially eradicates organisms on three occasions: (a) whilst wiping the skin with the isopropanol swab, (b) after injecting the local anaesthetic agent for skin and (c) whilst disinfecting the skin with chlorhexidine.

Despite being used commonly, the isopropanol method has drawn criticism, especially regarding the sterility of the technique. It could be argued that a breach in aseptic technique occurs with the injection of the local anaesthetic agent for skin analgesia prior to donning full sterile attire and disinfecting the skin with chlorhexidine-alcohol. This argument however, loses merit when one considers that the use of three to five swabs of isopropylalcohol has been shown to be non-inferior for the purpose of skin disinfection on the rate of contamination of blood culture specimens when compared with povidone-iodine. ${ }^{8}$

In addition, a point of criticism also arises on the skin disinfectant exposure time. The skin disinfectant exposure time equals the time from the application of the $0.5 \%$ chlorhexidine in $70 \%$ alcohol to the insertion of the needle into the subarachnoid or epidural space. This exposure time is decreased with the use of the isopropanol method. However, Sakuragi et al. demonstrated no growth of Staphylococcus aureus after 15 seconds of exposure to $0.5 \%$ chlorhexidine in $80 \%$ alcohol. ${ }^{9}$ Furthermore, Sakuragi et al. demonstrated that at a concentration of ethanol of $>60 \%$, both methicillin-resistant (MRSA) and methicillinsensitive Staphylococcus aureus (MSSA) were eradicated. ${ }^{9}$ In fact, at ethanol concentrations of $60 \%$ and $80 \%$, the MRSA and MSSA were eradicated within 15 seconds.

The isopropanol method utilises the rapid onset, effective bactericidal properties of isopropyl alcohol in addition to the bactericidal and sporicidal properties of $0.5 \%$ chlorhexidine in $70 \%$ alcohol. That being said, neither the isopropanol method nor the classic method has been shown to be superior to the other in its prevention of infectious complications after a neuraxial block. One should also consider that local anaesthetic agents (lignocaine and bupivacaine) possess antimicrobial properties. ${ }^{10,11}$ Injection of the local anaesthetic agent to the skin could theoretically eradicate the microorganisms residing in the deeper layers of the skin. There are however no studies that have investigated this theory of eradication of deeper lying bacteria by local anaesthetic agent administration. In addition, the bactericidal property of lignocaine is time dependent. Thus, a greater number of organisms may be eradicated by increasing the duration of exposure of the subcutaneous tissue to the local anaesthetic agents.

The question of which skin disinfection method is utilised for skin anaesthesia prior to neuraxial block, was brought to my attention via a conversation with a colleague [Firfiray, L. August 2015, personal communication]. During an inquiry on the development of septic meningitis in a patient post subarachnoid block, an expert witness testified that the use of only isopropanol swabs for skin disinfection before the administration of the local anaesthetic agent to skin prior to neuraxial block, was concerning and could have contributed to the development of septic meningitis after an uncomplicated subarachnoid block. It was concluded that the septic meningitis was caused during the performance of the subarachnoid block, although the exact cause and pathophysiology were uncertain.

The most recent South African Society of Anaesthesiologists guidelines on the aseptic performance of neuraxial anaesthesia, 
as well as other guidelines published by major international bodies, do not specify the preferred method of skin disinfection for cutaneous local anaesthesia administration prior to neuraxial block. ${ }^{12-14}$ In addition, the level of evidence for these guidelines is at expert opinion level only. The Royal College of Anaesthetist National Audit Project three (NAP3) did however find that not following published guidelines leads to an increase in complications following neuraxial blocks. ${ }^{15}$ There exists however, a paucity of data on the factors contributing to infectious complications associated with neuraxial blocks.

The question that we aimed to answer was how South African anaesthesiologists disinfect the skin prior to local anaesthetic agent administration to the skin, before neuraxial block. The objective of the study was to determine the preferred method used by anaesthesiologists to disinfect the skin before local anaesthetic administration, prior to the performance of a neuraxial block.

\section{Methods}

Ethics approval $(S 15 / 08 / 183)$ was granted prior to the commencement of this study by the Health Research Ethics Committee of Stellenbosch University, Faculty of Medicine and Health Sciences. The participation was voluntary. Electronic questionnaires were distributed, using the SoGoSurvey website, to various government employed anaesthetic service providers working in hospitals in the Republic of South Africa. The questionnaire consisted of 10 multiple choice questions: three questions regarding his/her demographics and seven questions regarding the study participants' technique (Figure 1). Exclusion criteria were medical professionals not working in anaesthesiology, anaesthesiologists working exclusively in private hospitals and medical interns rotating through anaesthesiology.

\begin{tabular}{|c|}
\hline 1. What is your total anaesthetic experience? \\
\hline 2. In which province do you currently work? \\
\hline 3. In which type of hospital do you most often work \\
\hline $\begin{array}{l}\text { 4. In the last } 6 \text { months, when performing a subarachnoid (spinal) } \\
\text { block, do you routinely administer a local anaesthetic agent to the } \\
\text { skin? }\end{array}$ \\
\hline $\begin{array}{l}\text { 5. In the last } 6 \text { months, when performing a subarachnoid (spinal) } \\
\text { block, which local anaesthetic agent do you routinely administer } \\
\text { to the skin? }\end{array}$ \\
\hline $\begin{array}{l}\text { 6. What is your routine sequence of events when you perform a } \\
\text { subarachnoid (spinal) block? }\end{array}$ \\
\hline $\begin{array}{l}\text { 7. In the last } 6 \text { months, when performing an epidural block, } \\
\text { do you routinely administer a local anaesthetic agent to the skin? }\end{array}$ \\
\hline $\begin{array}{l}\text { 8. In the last } 6 \text { months, when performing an epidural block, } \\
\text { which local anaesthetic agent do you routinely administer to the } \\
\text { skin? }\end{array}$ \\
\hline $\begin{array}{l}\text { 9. What is your routine sequence of events when you } \\
\text { perform an epidural block? }\end{array}$ \\
\hline $\begin{array}{l}\text { 10. To the best of your knowledge, has a central neuraxial block } \\
\text { (spinal or epidural) that you have personally performed, resulted } \\
\text { in a septic complication (e.g. epidural abscess; meningitis)? }\end{array}$ \\
\hline
\end{tabular}

Figure 1. Questions used as part of the survey on the preferred method used for disinfection of the skin before local anaesthetic agent administration prior to the performance of a neuraxial block
The heads of the relevant academic institutions in South Africa were e-mailed to explain the purpose of the study and to request the e-mail addresses of their anaesthetic service providers. A link to the questionnaire was sent electronically to the anaesthetic service providers in the various government hospital anaesthesiology departments. By clicking on the link, the relevant anaesthetic service providers were redirected to the SoGoSurvey website to complete the questionnaire. The anaesthetic service providers had six weeks to complete the questionnaire. Three e-mail reminders were sent to the participants that had not completed the questionnaire. An incentive scheme was constructed.

The estimated sample size before distribution of the questionnaire was 300 medical professionals. This was calculated by the number of anaesthetic service providers that indicated their willingness to participate in the survey. To limit nonresponder bias, a response rate of $30 \%$ was chosen as acceptable. A response rate of $>50 \%$ would signify an excellent response rate. Descriptive statistics were used on the raw data using the Fisher exact test to measure associations between the different categorical variables. A $p$-value of $<0.05 \%$ was regarded as statistically significant.

\section{Results}

Introductory e-mails totalling 296 were sent. All except one was delivered to the various anaesthetic service providers. Of the 295 introductory e-mails delivered, $89.5 \%$ (264/295) were read with a response rate of $60.3 \%(178 / 295)$ (Figure 2).

A little over half of the participants (52.3\% [92/176]) had equal or less than five years' experience, with the remainder $(47.7 \%$ [84/176]) having six or more years of experience. Most of the study participants were from the Western Cape (49.9\% [88/176]) with Limpopo, Mpumalanga, Eastern Cape and North West Province not represented in our study. Most (94.9\% [166/176]) of the study participants were from government teaching institutions with $1.7 \%(3 / 176)$ from private practice but affiliated with the teaching institution. Demographic data are presented in Tables II and III.

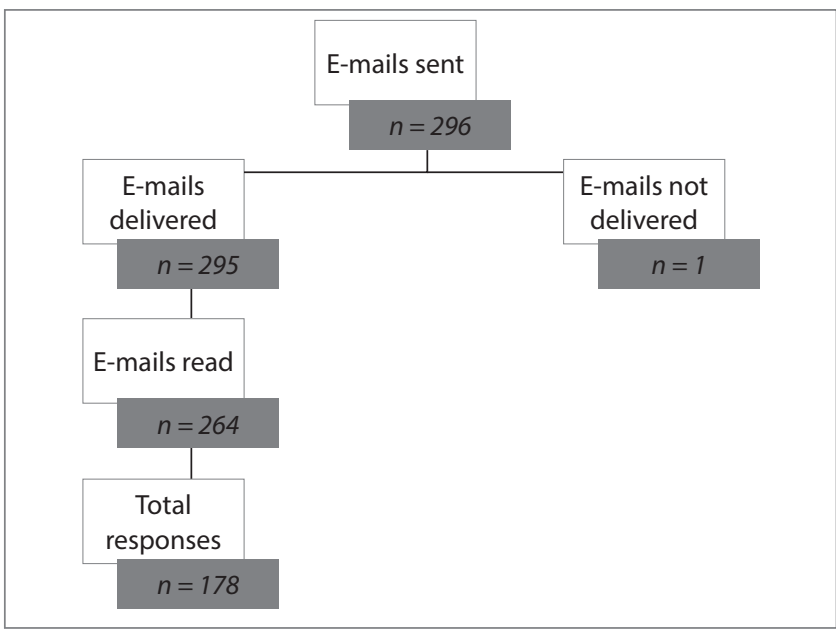

Figure 2. Flow chart of introductory e-mails sent, e-mails read and response rate 
Table II. Participants' experience in anaesthesiology in years

\begin{tabular}{lcc}
\hline & Number of participants & Percentage (\%) \\
\hline $\mathbf{5}$ years & 92 & 52.3 \\
$\mathbf{5 - 1 0}$ years & 38 & 21.6 \\
$\mathbf{1 0}$ years & 46 & 26.1 \\
& 176 & 100 \\
\hline
\end{tabular}

Table III. Distribution of participants by province in South Africa

\begin{tabular}{lcc}
\hline & $\begin{array}{c}\text { Number of } \\
\text { participants }\end{array}$ & Percentage (\%) \\
\hline Free State & 24 & 13.4 \\
\hline Gauteng & 44 & 24.7 \\
Kwazulu-Natal & 21 & 11.8 \\
\hline Northern Cape & 1 & 0.6 \\
Western Cape & 88 & 49.4 \\
\hline
\end{tabular}

Figure 3 represents the preferred method of local anaesthetic agent administration for both types of neuraxial blocks.

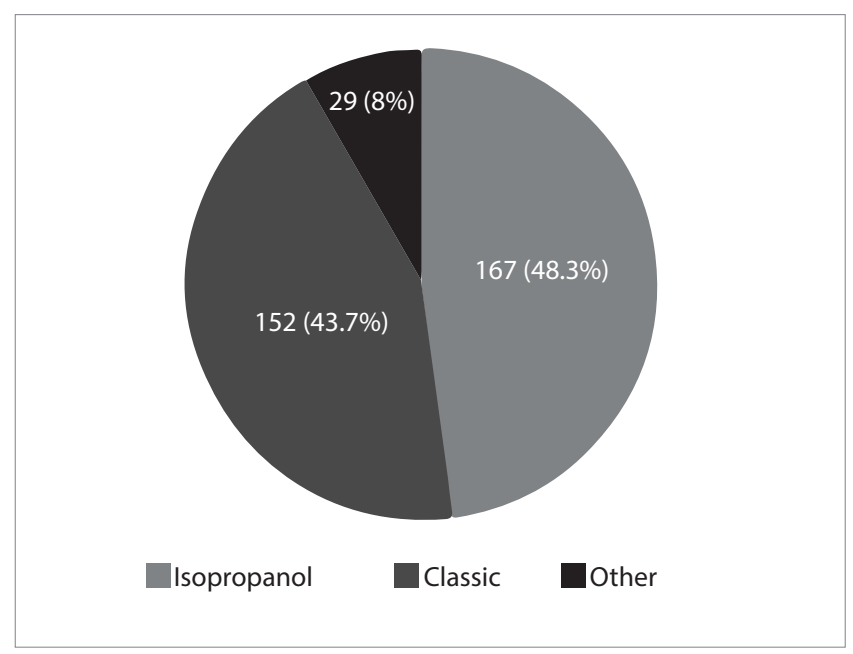

Figure 3. Preferred method of local anaesthetic administration in the performance of neuraxial blocks

\section{Subarachnoid blocks}

Just over half of the participants $(52.0 \%$ [90/173]) utilise the isopropanol method prior to a subarachnoid block, whereas $42.2 \%(73 / 173)$ of the participants utilise the classic method prior to a subarachnoid block. The remaining participants (5.8\% [10/173]) indicated that they utilise a different approach (Figure 4).

The proportional use of the isopropanol method is 60\% (51/85) amongst the Western Cape anaesthesiologists compared to $88.6 \%$ (39/44) amongst anaesthesiologists in Gauteng $(p<0.001)$. The majority $(74.4 \%$ [67/89]) of anaesthesiologists with zero to five years of experience use the isopropanol method whilst less than a quarter (20.9\% [9/89]) of anaesthesiologists with more than 10 years' experience use the isopropanol method $(p<0.001)$ (Figure 5).

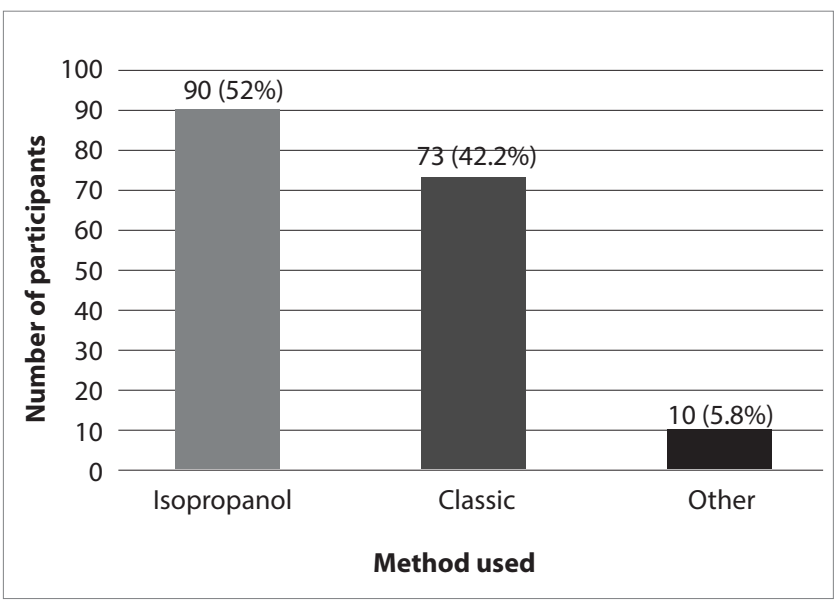

Figure 4. Preferred method of local anaesthetic administration before performing a subarachnoid block

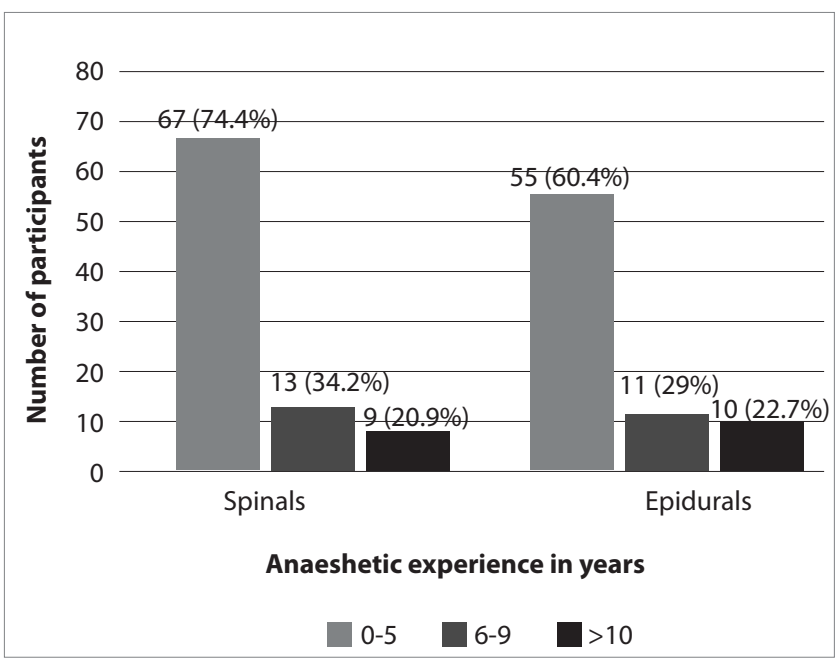

Figure 5. The use of the isopropanol method for neuraxial blocks by anaesthetics experience in years

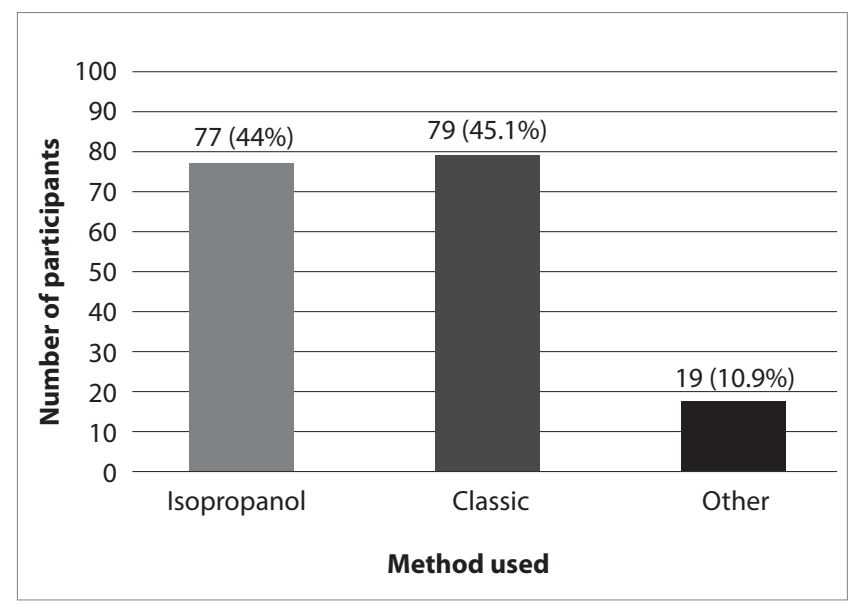

Figure 6. Preferred method of local anaesthetic administration before performing an epidural block

\section{Epidural blocks}

A little less than half (44.0\% [77/175]) of the participants utilise the isopropanol method for epidural blocks whereas $45.1 \%$ (79/175) of the participants utilise the classic method for epidural blocks. The remainder of participants (10.9\% [19/175]) indicated that they use a different method for epidural blocks. Some 
different approaches (10.9\% of participants) mentioned by the participants were variations of the classic method that included "gowning up" (Figure 6). The proportional use of the isopropanol method is 58.8\% (50/85) in the Western Cape anaesthesiologists compared to $61.4 \%(27 / 44)$ in Gauteng anaesthesiologists ( $p<0.001)$. The majority (60.4\% [55/91]) of anaesthesiologists with zero to five years' experience use the isopropanol method. In comparison, the majority (59.1\% [26/44]) of anaesthesiologists with more than 10 years' experience use the classic method $(p<0.001)$.

\section{Discussion}

The results of the study indicate that with regards to neuraxial blocks, one method of skin disinfection before local anaesthetic administration to the skin does not predominate over the other method.

That being said, this study was a survey of current practice and therefore no conclusion can be drawn on safe or unsafe practice with regards to skin disinfection before local anaesthetic agent administration to the skin prior to neuraxial block. Taking this into consideration, significant spinal and epidural needle contamination does still occur, even when adhering to strict aseptic techniques as described in the classic method. Raedler et al. demonstrated that when adhering to an aseptic technique (similar to the classic method in this study) and using povidone-iodine prior to the performance of subarachnoid block, significant needle contamination still occurred in $17.9 \%$ of needles, most organisms being common skin commensals. ${ }^{16}$ No mention was made on whether local anaesthetic agents were used prior to the performance of the subarachnoid block (as described in the isopropanol method) in Raedler's study, which could have affected results. Despite contamination of $17.9 \%$ of the needles used, none of the participants in Raedler's study developed septic complications.

Comparing the methods used in subarachnoid blocks versus epidural blocks, more participants prefer the isopropanol method for subarachnoid blocks compared to epidural blocks, where more participants prefer the classic method (Figures 4 and 6). It has been shown that the incidence of septic complications after an epidural block is higher when compared to the incidence after a subarachnoid block. ${ }^{15}$ This could explain the higher rate of use of the classic method when performing epidural blocks compared to subarachnoid blocks, seeing that the classic method is deemed the more sterile technique.

There is also a higher usage of the isopropanol method for both subarachnoid and epidural blocks in participants with less than five years' anaesthetic experience compared to participants with more than ten years' experience (Figure 5). The cause of this change in preference cannot be elucidated from this study. One might argue that the teaching of the performance of neuraxial blocks has changed, but a study investigating this theory has not been performed.
This is the first study investigating the preference in use of two different methods of skin disinfection prior to local anaesthetic agent infiltration of the skin, before the performance of a neuraxial block. The questionnaire was simple, convenient, relevant and quick to complete with the average time taken to complete the questionnaire being between three to four minutes. The use of an incentive scheme, the e-mail reminders and the introductory e-mail, all contributed to an excellent response rate of $60.3 \%$, thus limiting the non-response bias. Although five provinces were represented in the sample, four other provinces were not. In addition, anaesthesiologists in the private sector were not included, which led to sampling bias.

With any form of questionnaire or survey, the possibility exists of misinterpretation of the various methods described which could have influenced the participants' answers. The use of an incentive scheme could have influenced the final results by creating an environment where participants complete the questionnaire for the incentive and not to promote research.

\section{Conclusion}

There is limited data and evidence available on this topic. Although the neuraxial technique was initiated in the $19^{\text {th }}$ century, a standard of care has developed over the years and it will continue to evolve as the art of medicine is taught from one generation to the next. Anaesthesiology aseptic guidelines need to include the best method of skin disinfection before local anaesthetic agent administration to the skin prior to neuraxial block. ${ }^{12-14}$

Future studies should involve anaesthetic service providers from both private and public health sectors. The investigation of the theory of seeding of organisms into the deeper subcutaneous layers of the skin after skin puncture, is also warranted.

\section{Declaration}

We hereby declare that we conducted and completed this research. The study has not been submitted for publication in any other journal. This study was performed as part of a Masters of Medicine degree at the University of Stellenbosch.

\section{Conflict of interest}

\section{None}

\section{References}

1. Brill SI, Gurman GM, Fisher A. A history of neuraxial administration of local analgesics and opioids. Eur J Anaesthesiol. 2003;20(9):682-9.

2. Kent $C D$, Bollag $L$. Neurological adverse events following regional anesthesia administration. Local Reg Anesth. 2010;3(1):115-23.

3. Moen V, Dahlgren N, Irestedt L. Severe neurological complications after central neuraxial blockades in Sweden 1990-1999. Anesthesiology. 2004;101(4):950-9.

4. Horlocker TT, McGregor DG, Matsushige DK, Schroeder DR, Besse JA. A retrospective review of 4767 consecutive spinal anesthetics: central nervous system complications. Anesth Analg. 1997;84(3):578-84.

5. Strafford MA, Wilder RT, Berde CB. The risk of infection from epidural. Anesth Analg. 1995;80:234-8.

6. Sato $S$, Sakuragi T, Dan K. Human skin flora as a potential source of epidura abscess. Bd. 85, Anesthesiology. 1996. s. 1276-82.

7. Dippenaar J. Local anaesthetic agents. I: Milner A, Welch E, redaktørar. Applied Pharmacology in Anaesthesiology and Critical Care. First. Medpharm Publications; 2012. s. 331-81. 
8. Sutton $C D$, White $S A$, Edwards R, Lewis MH. A prospective controlled trial of the efficacy of isopropyl alcohol wipes before venesection in surgical patients. Ann $R$ Coll Surg Engl. mai 1999;81(3):183-6.

9. Sakuragi T, Yanagisawa K, Dan K. Bactericidal activity of skin disinfectants on methicillin-resistant Staphylococcus aureus. Anesth Analg. September 1995;81(3):555-8.

10. Feldman J, Chapin K, Turner J, Contant T. Do agents used for epidural analgesia have antimicrobial properties? Bd. 75, Anesthesiology. 2006. s. A835.

11. Sakuragi T, Ishino H, Dan K. Bactericidal activity of clinically used local anesthetics on Staphylococcus aureus. Reg Anesth. 1996;21(3):239-42.

12. Horlocker TT, Birnbach DS, Connis RT, Nickinovich DG, Palmer CM, Pollock JE, mfl. Practice Advisory for the prevention, diagnosis, and management of infectious complications associated with neuraxial techniques: A report by the American
Society of Anestheiologists task force on infectious complications associated with neuraxial techniq. Anesthesiology. 2010;112(3):530-45.

13. Samuel R, Nel D, Joubert I, De Bruin J, Dwyer S, Fourie A, mfl. SASA guidelines for infection control in anaesthesia in South Africa 2014 SASA Guidelines for Infection Control in. SAJAA. 2014;20(3):S1-39.

14. Campbell JP, Plaat F, Checketts MR, Bogod D, Tighe S, Moriarty A. Safety guideline: skin antisepsis for central neuraxial block. Association of Anaesthetists of Great Britain and Ireland. Anaesthesia. 2014;69(September):1279-86.

15. Cook T. The 3rd National Audit Project of The Royal College of Anaesthetists: Major complications of central neuraxial block in the united kingdom. 2009.

16. Raedler C, Lass-Flörl C, Pühringer F, Kolbitsch C, Lingnau W, Benzer A. Bacterial contamination of needles used for spinal and epidural anaesthesia. $\mathrm{Br} J$ Anaesth 1999;83(4):657-8. 